\title{
Maternal Risk factors, morbidity, and mortality pattern of LBW babies admitted in NICU: A Retrospective study done in Banas Medical College and Research Centre, Palanpur, Gujarat, India
}

\author{
K Shrivastava A. ${ }^{1}$, Sharma N. ${ }^{2 *}$, K. Roy S. ${ }^{3}$, R. Desai H. ${ }^{4}$, A. Hasan A. ${ }^{5}$ \\ DOI: https://doi.org/10.17511/ijpr.2020.i06.01
}

1 Ajit K Shrivastava, Associate Professor and Head, Department of Pediatrics, Banas Medical College and Research Institute, Palanpur, Gujarat, India.

2* Neha Sharma, Assistant Professor, Department of Pediatrics, Banas Medical College and Research Institute, Palanpur, Gujarat, India.

3 Santosh K. Roy, Assistant Professor, Department of Pediatrics, Banas Medical College and Research Institute, Palanpur, Gujarat, India.

${ }^{4}$ Heenaben R. Desai, Assistant Professor, Department of Pediatrics, Banas Medical College and Research Institute, Palanpur, Gujarat, India.

5 Anjum A. Hasan, Senior Resident, Department of Pediatrics, Banas Medical College and Research Institute, Palanpur, Gujarat, India.

Background: This study was undertaken to know about the maternal risk factors, morbidity, and mortality of low birth weight (LBW) babies admitted to NICU in a tertiary care hospital. Methods: This is a hospital-based, retrospective, descriptive study, done on LBW babies admitted to the NICU of Banas Medical College and Research Institute, Palanpur from January 2019- March 2020. Results: Out of the 1018 newborns admitted to NICU, 735 were LBW babies and 700 LBW babies were analyzed because 35 cases did not fit in inclusion criteria. The magnitude of LBW babies was $68.7 \%$.Out of 700 LBW babies, 530 (75.7\%) had weight between $1.5 \mathrm{~kg}$ to $2.49 \mathrm{~kg}, 138$ (19.7\%) babies were of VLBW ( $1 \mathrm{~kg}-1.5 \mathrm{~kg})$ and $32(4.57 \%)$ babies were of ELBW (weight $<1 \mathrm{~kg}$ ). Out of 700 LBW babies, 450 (64.3\%)were males and 250(35.7\%) were females and $60(8.57 \%)$ were term babies and 640 (91.42\%)were preterm babies. Among the maternal risk factors most common was maternal undernutrition (30\%), followed by maternal anemia in 180 cases (25.7\%), inadequate ANC visits in 170 cases (24.2\%), maternal age <20 years in 110 cases (15.7\%). Conclusion: Identification of maternal risk factors and providing proper care and appropriate management to LBW can reduce neonatal morbidity and mortality

Keywords: Neonatal intensive care unit, LBW babies, Maternal Risk factors, Morbidity, Mortality

Corresponding Author

Neha Sharma, Assistant Professor, Department of Pediatrics, Banas Medical College and Research Institute, Palanpur, Gujarat, India.

Email: nehu.sharma8785@gmail.com
How to Cite this Article

To Browse
Shrivastava AK, Sharma N, Roy SK, Desai HR, Hasan AA. Maternal Risk factors, morbidity, and mortality pattern of LBW babies admitted in NICU: A Retrospective study done in Banas Medical College and Research Centre, Palanpur, Gujarat, India. Pediatric Rev Int J Pediatr Res. 2020;7(6):222-227. Available From

https://pediatrics.medresearch.in/index.php/ijpr/arti cle/view/605

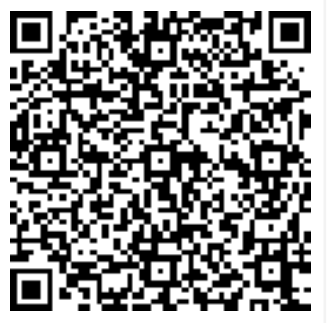




\section{Introduction}

LBW is a major public health problem in India and it contributes significantly to infant mortality as mortality of LBW babies is 40 times more than the normal-weight babies [1]. According to the World Health Organization (WHO) definition, infants with birthweight less than $2500 \mathrm{~g}$ are low birth weight (LBW) [2]. There are almost 23 million LBW infants from 121 million births in a year, a high proportion of which are in developing countries [1]. The incidence of LBW is estimated to be $16 \%$ worldwide, $90 \%$ in the least developed and developing countries [3], and $7 \%$ in the developed countries. LBW babies have a higher risk of morbidity and mortality relative to the risk in an infant of normal birth weight. These babies are at an increased risk of asphyxia, hypoglycemia, polycythemiahyperviscosity, hypothermia. and are more prone to have impaired neurodevelopment and diabetes mellitus in adult life [4]. In most developing countries it was approximated that every ten seconds an infant die from a disease or infection that can be attributed to low birth weight [5]. Low birth weight can be caused either by premature delivery (short gestation) or by fetal growth retardation. Known factors for pre-term delivery and fetal growth retardation which are associated with LBW include low maternal food intake, hard physical work during pregnancy, and illness, especially infections $[6,7]$. Several studies suggest that cigarette smoking, genetic and environmental factors can cause LBW [8]. Short maternal stature, very young age, high parity, close birth spacing, high C8 cell counts in HIV infections are all associated factors $[9,10]$. This study was undertaken to find maternal risk factors, morbidity, and mortality patterns of low birth weight babies.

\section{Materials and Methods}

Setting: Hospital-based study done in Banas Medical College and Research Institute, Palanpur, Gujarat

Duration and type of study: Hospital-based, retrospective, descriptive study done from January 2019- March 2020.

Sampling methods: Based on all babies who fulfilled inclusion criteria

Sample size calculation: All LBW babies admitted and treated in NICU from January 2019- March 2020 were included.
Inclusion Criteria: LBW babies admitted and treated in NICU from January 2019- March 2020

Exclusion Criteria: Babies with inadequate data.

Babies with life-threatening congenital malformations

Data collection procedure: Hospital Registration number of LBW babies was identified from the NICU Nominal Register and their case sheets were retrieved from the medical records department. Data was taken regarding maternal risk factors, morbidity, and mortality pattern of LBW babies from medical records.

Any scoring system: Gestational age was assessed by the Modified Ballard Score method as found in case sheets.

Mothers with less than three antenatal check-ups (ANC) visits to health care facilities were defined to have inadequate ANC visits. Maternal undernutrition was defined as a body mass index $<18.5 \mathrm{~kg} / \mathrm{m} 2$. The gestational age (GA) was assessed using the date of the last menstrual period and confirmed by the Modified Ballard Score method. Blood sugar level $<40 \mathrm{mg}$ per decilitre was defined as hypoglycemia. Axillary temperature below $35.50 \mathrm{~F}$ was defined as severe hypothermia as per the WHO Integrated Management of Childhood Illness guideline. Any level of serum bilirubin requiring intervention was defined as non-physiological hyperbilirubinemia [11]. Morbidities like birth asphyxia (HIE), sepsis, jaundice, Respiratory Distress Syndrome (RDS), Apnoea of prematurity, Meconium aspiration syndrome (MAS) were predefined. Morbidity and Mortality pattern of LBW babies was noted.

\section{Results}

Out of the 1018 newborns admitted to NICU, 735 were LBW babies and 33 were excluded because of insufficient data, and 2 were excluded because they had life-threatening congenital malformation. Perinatal characteristics, maternal risk factors, and outcomes of the remaining 700 LBW babies were analyzed. The magnitude of LBW babies was 68.7 $\%$.Out of 700 LBW babies ,530 $(75.7 \%)$ had weight between $1.5 \mathrm{~kg}$ to $2.5 \mathrm{~kg}, 138(19.7 \%)$ babies were of VLBW $(1 \mathrm{~kg}-1.5 \mathrm{~kg})$ and $32(4.57 \%)$ babies were of ELBW (weight $<1 \mathrm{~kg}$ ). Out of 700 LBW babies, 450 $(64.3 \%)$ babies were males and $250(35.7 \%)$ were females and $60(8.57 \%)$ were term and 640 $(91.42 \%)$ were preterm babies. 
Table-1: Characteristics of LBW babies admitted in NICU $(n=700)$.

\begin{tabular}{|l|l|l|}
\hline \multicolumn{1}{|c|}{ Data } & \multicolumn{1}{|c|}{ Number } & \multicolumn{1}{|l|}{ Percentage } \\
\hline Classification of LBW & 700 & $68 \%$ \\
\hline Gestational age & 60 & $8.57 \%$ \\
\hline Term babies & 640 & $91.42 \%$ \\
\hline Preterm babies & \multicolumn{2}{l}{} \\
\hline Birth weight & 32 & $4.57 \%$ \\
\hline$<1 \mathrm{~kg}$ & 138 & $19.7 \%$ \\
\hline $1-1.5 \mathrm{~kg}$ & 530 & $75.7 \%$ \\
\hline $1.5-2.49 \mathrm{~kg}$ & \multicolumn{2}{|l}{} \\
\hline Gender & 450 & $64.3 \%$ \\
\hline Male & 250 & $35.7 \%$ \\
\hline Female &
\end{tabular}

Among the maternal risk factors most common was maternal undernutrition (30\%), followed by maternal anemia in 180 cases $(25.7 \%)$, inadequate ANC visits in 170 cases (24.2\%), maternal age <20 years in 110 cases (15.7\%). Less common causes were bad obstetric history (1.14\%), Twins delivery $(1 \%)$, acute infections, and elderly primi in $(0.85 \%)$ respectively and the least common was PROM in $0.42 \%$ cases.

Table-2: Maternal risk factors associated with LBW babies $(\mathbf{n}=700)$.

\begin{tabular}{|l|l|l|}
\hline \multicolumn{1}{|c|}{ Maternal risk factors } & \multicolumn{1}{c|}{ Number } & \multicolumn{1}{c|}{ Percentage } \\
\hline Maternal undernutrition & 210 & $30 \%$ \\
\hline Maternal anemia & 180 & $25.7 \%$ \\
\hline Inadequate ANC visits & 170 & $24.2 \%$ \\
\hline Maternal age <20 years & 110 & $15.7 \%$ \\
\hline Bad obstetric history & 8 & $1.14 \%$ \\
\hline Twins delivery & 7 & $1 \%$ \\
\hline Acute infections & 6 & $0.85 \%$ \\
\hline Elderly primi & 6 & $0.85 \%$ \\
\hline PROM & 3 & $0.42 \%$ \\
\hline
\end{tabular}

Out of 700 LBW babies, morbidity was seen in 590 LBW babies (84.28\%). Most common cause of morbidity was sepsis in $91(15.4 \%)$ cases followed by jaundice in $90(15.25 \%)$ cases, feeding difficulties in $82(13.9 \%)$, hypothermia in 68 $(11.5 \%)$, hypoglycemia in $56(9.5 \%)$, AOP in $50(8.47 \%)$, RDS in 45 cases $(7.62 \%)$. Less common causes were seizures in $30(5 \%)$, MAS in 28 (4.74\%), HIE in 20 (3.389\%), TTNB in 20 (3.38\%), and least common was a congenital anomaly in 10 $(1.69 \%)$. Mortality was seen in 110 cases $(15.7 \%)$. The most common cause of mortality was sepsis in 40 cases $(36.36 \%)$, extreme prematurity, and RDS in $20(18.18 \%)$ cases respectively, ELBW with IVH in $15(13.6 \%)$ and AOP in $12(11 \%)$ cases.
The least common cause was MAS with PPHN in 3 $(2.72 \%)$ cases.

Table-3: Morbidity and Mortality Pattern of LBW babies $(n=700)$.

\begin{tabular}{|l|l|l|}
\hline \multicolumn{1}{|c|}{ Data } & Number & Percentage \\
\hline Morbidity pattern & 590 & 84.28 \\
\hline Sepsis & 91 & 15.4 \\
\hline Jaundice & 90 & 15.25 \\
\hline Feeding difficulties & 82 & 13.89 \\
\hline Hypothermia & 68 & 11.5 \\
\hline Hypoglycemia & 56 & 9.49 \\
\hline Apnoea of prematurity & 50 & 8.47 \\
\hline HMD - hyaline membrane disease & 45 & 7.62 \\
\hline Seizures & 30 & 5.08 \\
\hline MAS - Meconium aspiration syndrome & 28 & 4.74 \\
\hline HIE & 20 & 3.38 \\
\hline TTNB- transient tachypnoea of new-born & 20 & 3.38 \\
\hline Congenital anomalies & 10 & 1.69 \\
\hline Mortality pattern & 110 & 15.7 \\
\hline Sepsis & 40 & 36.36 \\
\hline extreme prematurity & 20 & 18.18 \\
\hline RDS & 20 & 18.18 \\
\hline ELBW with IVH & 15 & 13.6 \\
\hline AOP & 12 & 10.9 \\
\hline MAS with PPHN & 3 & 2.72 \\
\hline & & \\
\hline
\end{tabular}

\section{Discussion}

In the present study magnitude of LBW babies admitted in the NICU was $68 \%$. A study done by Tushar et al in Gujarat found the magnitude of LBW babies to be 56\%[12]. Another study done by Deswal et al in 1999 from India found the incidence of LBW to be about $9.14 \%$ [13].

In the present study, 64.3\% (450) were males and $35.7 \%$ (250) were females. Mannan MA et al. in Bangladesh (2012) showed that $62.86 \%$ of VLBW babies in their study were males showing male sex as a risk factor for VLBW delivery [14] Naskar $N$ et al also found in their study that majority of VLBW babies admitted were males(57.53\%)[15]

In the present study $91.42 \%$ (640) LBW babies were preterm while only $8.57 \%$ (60) were term babies. Manganaro et al (1991) [16], Mannan MA et al. [14] (2012), and Roy et al. (2006) [17] found similar results in their studies. In literature, twothirds of infants born weighing less than 2,500 grams are preterm [18].

In the present study distribution among birth weight showed that ELBW ( $<1 \mathrm{~kg}$ ) babies were 32 (4.57\%) 
VLBW babies were ( 1 to $1.5 \mathrm{~kg}$ ) 138 (19.7\%), and 1.5 to $2.49 \mathrm{~kg}$ were $530(75.7 \%)$. In a study done by Chidiebere ODI et al, $12.0 \%$ of babies were of ELBW, $28.1 \%$ babies were of VLBW while $59.9 \%$ had weights between $\geq 1.5-2.5 \mathrm{~kg}$ [19].

In the present study, among the maternal risk factors, the most common was maternal undernutrition in 210 (30\%) cases. Maternal prepregnancy BMI plays an important role in determining the birth weight of the baby. One explanation for the lower mean neonate birth weight in women with low pre-pregnancy weight may be that the fetus was prevented from receiving an adequate supply of nutrients from the mother because of changes in maternal hemodynamic status [20].

This was followed by maternal anemia in 180 $(25.7 \%)$ cases. It was shown that for women with iron deficiency the mean weight of their infants was $242 \mathrm{~g}$ less, and the risk of LBW was significantly greater among women with moderate anemia compared with those without anemia [21]. This was followed by inadequate ANC visits in 170 (24.2\%) cases, maternal age $<20$ years in 110 cases $(15.7 \%)$. Less common causes were bad obstetric history (1.14\%), Twins delivery (1\%), acute infections and elderly primi $(0.85 \%)$, and least common was PROM in $0.42 \%$. T Parikh et al, Naskar $\mathrm{N}$ et al also found similar maternal risk factors to be associated with LBW babies $[12,15]$.

According to the outcome, out of 700 LBW babies, morbidity was seen in 590 LBW babies (84.28\%). Common causes of morbidity were sepsis in 91 $(15.4 \%)$, jaundice in $90(15.25 \%)$, feeding difficulties in $82(13.9 \%)$, hypothermia in 68 $(11.5 \%)$, hypoglycemia in $56(9.5 \%)$, AOP in 50 $(8.47 \%)$, RDS in 45 cases $(7.62 \%)$. Less common causes were seizures in $30(5 \%)$, MAS in 28 (4.74\%), HIE in 20 (3.389\%), TTNB in 20 (3.38\%), and least common was congenital anomaly in 10 $(1.69 \%)$ cases. Mortality was seen in 110 cases $(15.7 \%)$. The most common cause of mortality was sepsis in 40 cases (36.36\%) followed by extreme prematurity and HMD in 20 (18.18\%) cases respectively, ELBW with IVH in 15 (13.6\%), AOP in $12(11 \%)$. The least common cause was MAS with PPHN in $3(2.72 \%)$.

In a study done by Poudel $\mathrm{P}$ et al in Nepal, it was found that most common cause of morbidity among VLBW babies was clinical sepsis (77.1\%) followed by non-physiological hyperbilirubinemia (73.6\%),
Apnoea (48.6\%), shock (42.9\%), hypoglycemia (39.3\%), anemia $(29.3 \%)$, hyaline membrane disease (HMD, 21.4\%), patent ductus arteriosus $(15.0 \%)$, severe hypothermia $(12.1 \%)$, cultureproven sepsis $(15.7 \%)$, retinopathy of prematurity $(5.7 \%)$, and bronchopulmonary dysplasia (3.6\%). Overall survival was $54.3 \%$ and major causes of death were HMD (51.0\%) and sepsis (34.7\%) [22]. In a prospective observational study done by Tagare et al, Respiratory distress syndrome (RDS), intraventricular hemorrhage (IVH), pulmonary hemorrhage and sepsis were the major causes of death, while RDS, sepsis, and hyperbilirubinemia were the most common morbidities during the neonatal period [23].

\section{Limitations}

This study does not provide any scope for follow up of LBW babies and as it is a hospital-based study it does not reflect about prevalence, morbidity, and mortality pattern of LBW babies in the community.

\section{Conclusion}

LBW is a common problem in India which contributes significantly to neonatal mortality rate. In the present study, it was found that maternal undernutrition, maternal anemia, inadequate ANC visits were most commonly associated with LBW. Therefore all interventions must be taken to give proper antenatal care to mothers like educating them regarding the importance of proper diet in pregnancy, intake of iron tablets during pregnancy, maintaining hygiene, screening for infections, avoiding successive pregnancies, avoidance of teenage and elderly pregnancy, etc to prevent LBW.LBW babies should be given proper care in NICU in form of safe and infection-free environments, surfactant therapy and ventilation should be made a priority and health care personnel should be more responsible in caring for these babies.

\section{What does this study add to existing knowledge?}

Prematurity and LBW are the leading cause of neonatal mortality. As seen in this study, maternal health and antenatal care predominantly affect the birth weight of the baby. Therefore, all steps should be taken to improve maternal health and general wellbeing in order to improve the neonatal mortality rate. 


\section{Author's contribution}

Dr. Ajit K. Shrivastava: Study design

Dr. Neha Sharma: Study design, collection of data

Dr. Santosh K. Roy: Collection of data

Dr. Heenaben R. Desai: Data analysis

Dr. Anjum A. Hasan: Data analysis

\section{Acknowledgments}

The authors would like to thank all MRD and NICU staff for helping us in collecting data.

\section{Reference}

01. Roudbari M, Yaghmaei M, Soheili M. Prevalence, and risk factors of low-birth-weight infants in Zahedan, Islamic Republic of Iran. EMHJEastern Mediterr Health J. 2007;13(4)838-845. [Crossref]

02. Behrman RE, Kliegman RM, eds. Nelson essentials of pediatrics. 4th ed; Philadelphia, WB Saunders. 2002.

[Crossref]

03. McCormick MC. The contribution of low birth weight to infant mortality and childhood morbidity. New Eng J Med. 1985;312(2)82-90.

[Crossref]

04. Stoll BJ, Kliegman RM. High risk infant InBehrman RE, Kliegman RM, Jenson HB, editors Nelson textbook of Paediatrics. 17th Edition; Philadelphia- Saunders. 2004;547-559.

[Crossref]

05. Villar J, Belizán J. The relative contribution of prematurity and fetal growth retardation to low birth weight in developing and developed societies. Am J Obstet Gynecol. $1982 ; 143(7) 793-798$.

[Crossref]

06. Klingenberg C, Olomi R, Oneko M, Sam N, Langeland $\mathrm{N}$. Neonatal morbidity and mortality in a Tanzanian tertiary care referral hospital. Annals Trop Paediatr. 2003;23(4)293-299.

[Crossref]

07. Kusin JA, Kardjati S, Renqvist UH. Maternal body mass index- the functional significance during reproduction. Europe J Clin Nutri. 1994. [Crossref]
08. Bang AT, Bang RA, Baitule SB, Reddy $M H$, Deshmukh MD. Effect of home-based neonatal care and management of sepsis on neonatal mortality- field trial in rural India. Lancet. 1999;354(9194)1955-1961.

[Crossref]

09. UNAIDS. AIDS epidemic update Geneva- United Nations Administrative Committee on Coordination Sub Committee on Nutrition (2000). Low Birth Weight- Nutrition Policy. 2000; Paper No 18.

[Crossref]

10. Verma V, Das KB. Teenage primigravidae- a comparative study. Indian J Public Health. 1997;41(2)52-55.

[Crossref]

11. McIntrire DD, Bloom SL, Casey BM, Leveno KJ. Birth weight in relation to morbidity and mortality among new born infants. N Engl J Med. 1999;340(16)1234-1238.

[Crossref]

12. Parikh T, Parikh A. Maternal risk factors and outcome of low birth weight babies admitted to a Gujarat Adani Institute of Medical Science, Bhuj, Kutch, Gujarat, India- A cross-sectional study. Int J Med Paediatr Oncol. 2017;3(2)5456.

[Crossref]

13. Deswal BS, Singh JV, Kumar D. A study of Risk factors for low birth weight. Indian J Comm Med. 1999;24(3)127-131.

[Crossref]

14. Mannan MA, Jahan N, Dey SK, Uddin MF, Ahmed S. Maternal and foetal risk factor and complication with immediate outcome during hospital stay of very low birth weight babies. Mymensingh Med J- MMJ. 2012;21(4)639. [Crossref]

15. Naskar N, Swain A, Das KN, Patnayak AB. Maternal risk factors, complications and outcome of very low birth weight babiesprospective cohort study from a tertiary care centre in Odisha. J Neonatal Biol. 2014;3;21670897.

[Crossref]

16. Roy KK, Baruah J, Kumar S, Malhotra N, Deorari AK, Sharma JB. Maternal antenatal profile and immediate neonatal outcome in VLBW and ELBW babies. Indian J Pediatr. 2006;73(8)669. [Crossref] 
17. Scholl TO, Johnson WG. Folic acid influence on the outcome of pregnancy. Am J Clin Nutri. 2000;71(5)1295S-1303S.

[Crossref]

18. Manganaro R, Gemelli M, Mami C, Mancuso A, Rizza ML, Leonardi R. Analysis of factors associated with very low birth weight (less than or equal to $1500 \mathrm{~g}$ ). Minerva ginecologica. $1991 ; 43(6) 283-286$.

[Crossref]

19. Poudel P, Budhathoki S, Shrivastava MK. Maternal risk factors and morbidity pattern of very low birth weight infants- A NICU based study at eastern Nepal. J Nepal Paediatr Soc. 2009;29(2)59-66.

[Crossref]

20. Tagare A, Chaudhari S, Kadam S, Vaidya U, Pandit A, Sayyad MG. Mortality and morbidity in extremely low birth weight (ELBW) infants in a neonatal intensive care unit. Indian J Pediatr. 2013;80(1)16-20.

[Crossref]
21. Chidiebere ODI, Uchenna E, Ikenna KN, Christian I, Nwabueze AI, Ogechukwu FA. The Low-birth weight Infants- Pattern of Morbidity and Mortality in a tertiary Health care Facility in the South Eastern Nigeria. Ann Med Health Sci Res. $2018 ; 8 ; 4-10$.

[Crossref]

22. Steer PJ. Maternal hemoglobin concentration and birth weight. Am J Clin Nutri. 2000;71(5)1285S-1287S.

[Crossref]

23. Ronnenberg AG, Wood RJ, Wang $X$, Xing $H$, Chen $\mathrm{C}$, et al. Preconception hemoglobin and ferritin concentrations are associated with pregnancy outcome in a prospective cohort of Chinese women. J Nutri. 2004,134(10)25862591.

[Crossref] 